\title{
Expression levels of microRNA-455 and its potential functions by targeting IGF-1R in melanoma
}

\author{
HUI WANG ${ }^{1}$, LIANG YU ${ }^{2}$ and XIUJUAN SHAN ${ }^{1}$ \\ Departments of ${ }^{1}$ Dermatology and ${ }^{2}$ Clinical Laboratory, Weifang People's Hospital, Weifang, Shandong 261041, P.R. China
}

Received January 3, 2016; Accepted February 3, 2017

DOI: $10.3892 / \mathrm{mmr} .2017 .6468$

\begin{abstract}
Melanoma has the highest fatality and malignancy of all skin cancers. In cancer, microRNAs (miRNAs) act as tumor suppressors or oncogenes, and inactivation of oncogenic miRNAs or restoration of tumor suppressor miRNAs has potential for cancer treatment. In the present study, miR-455 expression levels were examined in melanoma tissues and cell lines, and miR-455 was significantly downregulated in melanoma compared with matched normal tissues or normal epidermal melanocytes. In addition, increasing miR-455 expression in melanoma cells reduced cell proliferation and invasion. Bioinformatic analysis revealed that insulin-like growth factor 1 receptor (IGF-1R) was a putative target of miR-455. Luciferase reporter assays, reverse transcription-quantitative polymerase chain reaction and western blot confirmed that miR-455 targeted the 3'-untranslated region of IGF-1R and thus regulated the biological processes of melanoma cells. IGF-1R knockdown resulted in similar effects as miR-455 overexpression in melanoma cells. In summary, these findings indicated that miR-455 was downregulated in melanoma, and inhibited proliferation and invasion of melanoma cells through directly targeting IGF-1R. This also suggested that the restoration of miR-455 may be worth investigation as a therapeutic treatment for patients with melanoma.
\end{abstract}

\section{Introduction}

Melanoma, a life-threatening malignancy that arises from melanocytes, is the fifth most common neoplasia in human and accounts for $80 \%$ of skin cancer-associated mortality (1). It is characterized by aggressive invasion, early metastasis and resistance to chemotherapy or radiotherapy (2). In the past few decades, the morbidity of melanoma has been increasing by

Correspondence to: Professor Xiujuan Shan, Department of Dermatology, Weifang People's Hospital, 151 Guangwen Road, Weifang, Shandong 261041, P.R. China

E-mail: xiujuan_shan@163.com

Key words: melanoma, IGF-1R, miR-455, proliferation, invasion, therapy
3-8\% per year in Western countries (3). Although most patients with melanoma present with localized disease that is curable with surgical resection $(4,5)$, for those with regional or distant metastasis the prognosis is poor, with 10 -year survival rates of 64 and 16\%, respectively (6). Previous progress in understanding the molecular mechanisms underlying melanoma has brought about the development of new targeted therapies, including vemurafenib, which targets a B-Raf proto-oncogene, serine/threonine kinase $(R A F 1) \mathrm{V} 600$ activating mutation and has produced significant anti-tumor responses in clinical studies (7). However, immunotherapy, chemotherapy, small molecule inhibitors or targeted therapies are not effective in most melanoma cases $(8,9)$. Therefore, it is necessary to investigate the biology of melanoma initiation and progression and develop effective therapeutic strategies.

icroRNAs (miRNAs) are a novel group of endogenous, single-stranded and short non-coding RNA molecules of 18-25 nucleotides (10). They negatively regulate gene expression through base-pair interactions between $5^{\prime}$ ends of miRNA and target regions within the 3 '-untranslated region (3'UTR) of mRNA, resulting in translation inhibition or induction of mRNA degradation (11). At present, $>1,000$ miRNAs have been identified in humans, and they modulate more than a third of the human genome (12). Previous studies have reported that miRNAs are involved in the pathogenesis of multiple human diseases, including cancer, and are involved in multiple cellular processes including cell proliferation, apoptosis, differentiation, carcinogenesis, metastasis and drug resistance (13-15). Abnormal expression of miRNAs is associated with human cancers, and has been demonstrated to contribute to carcinogenesis and progression of cancers, including melanoma (16-18). In cancers, miRNAs act as tumor suppressors or oncogenes, and inactivation of oncogenic miRNAs or restoration of tumor suppressor miRNAs has great potential for cancer treatment (19-21).

In the present study, the functional involvement of miR-455 in melanoma was investigated, and miR-455 was demonstrated to act as a tumor suppressor in melanoma. The expression of miR-455 was downregulated in melanoma tissues compared with normal tissues, and this was also observed in melanoma cell lines and human epidermal melanocytes. Restoration of miR-455 expression inhibited cell proliferation and invasion of melanoma cells. Furthermore, insulin-like growth factor 1 receptor (IGF-1R) was identified as a direct target gene of $\operatorname{miR}-455$. 


\section{Materials and methods}

Tissue samples, cell lines and oligonucleotide transfection. The present study was approved by the Ethics Committee of Weifang People's Hospital (Weifang, China). Written informed consent for research purposes was provided by the participants. A total of 20 paired melanoma tissues and adjacent non-tumor tissues were collected from patients with melanoma who underwent operations at Weifang People's Hospital between July 2013 and April 2015. All patients were diagnosed with melanoma and were not treated with radiotherapy or chemotherapy prior to surgery. Tissue specimens were snap-frozen in liquid nitrogen and stored at $-80^{\circ} \mathrm{C}$ until use.

Human melanoma cell lines (SKMEL1, A375, HT144, A2058) and a human embryonic kidney cell line (HEK293T) used for luciferase reporter assays were obtained from the American Type Culture Collection (Manassas, VA, USA). The cells were cultured in RPMI-1640 medium or Dulbecco's modified Eagle's medium (DMEM; Gibco; Thermo Fisher Scientific, Inc., Waltham, MA, USA), supplemented with $10 \%$ fetal bovine serum (FBS), $100 \mathrm{mg} / \mathrm{ml}$ penicillin and $100 \mathrm{mg} / \mathrm{ml}$ streptomycin. Human epidermal melanocytes (HEM) were purchased from ScienCell Research Laboratories, Inc. (San Diego, CA, USA) and maintained in melanocyte medium (ScienCell Research Laboratories, Inc.) according to the manufacturer's protocol. All cells were cultured in a humidified $5 \% \mathrm{CO}_{2}$ cell incubator at $37^{\circ} \mathrm{C}$.

The miR-455 mimic, negative control (NC) mimic, IGF-1R siRNA and scramble siRNA control were synthesized by Guangzhou RiboBio Co., Ltd (Guangzhou, China). The sequence of the IGF-1R siRNA was 5'-GCCGATGTGTGA GAAGACC-3' and the scramble siRNA control sequence was 5'-AACAGGCACACGTCCCAGCGT-3'. Cells were transfected with oligonucleotides using Lipofectamine 2000 (Invitrogen; Thermo Fisher Scientific, Inc.) according to the manufacturer's protocol.

Reverse transcription-quantitative polymerase chain reaction $(R T-q P C R)$. Total RNA was isolated from tissues and cells using TRIzol reagent (Invitrogen; Thermo Fisher Scientific, Inc.) according to the manufacturer's protocol. The quantity of total RNA was determined using the ND-1000 NanoDrop spectrophotometer (NanoDrop Technologies; Thermo Fisher Scientific, Inc.). For miR-455 expression, total RNA was reverse transcribed into cDNA using the TaqMan miRNA reverse transcription kit (Applied Biosystems; Thermo Fisher Scientific, Inc.) and RT-qPCR was performed using TaqMan Universal Master Mix II (Applied Biosystems; Thermo Fisher Scientific, Inc.). U6 was measured as an internal control for miR-455 expression. The thermocycling conditions were as follows: $95^{\circ} \mathrm{C}$ for $10 \mathrm{~min}$; 40 cycles of denaturation at $95^{\circ} \mathrm{C}$ for $15 \mathrm{sec}$ and annealing at $60^{\circ} \mathrm{C}$ for $1 \mathrm{~min}$; and a final elongation step at $72^{\circ} \mathrm{C}$ for $10 \mathrm{~min}$. For IGF-1R mRNA expression, total RNA was reverse transcribed into cDNA using the PrimeScript RT Reagent kit (Takara Biotechnology Co., Ltd., Dalian, China), followed by RT-qPCR using SYBR-Green PCR master mix (Takara Biotechnology Co., Ltd.). Glyceraldehyde 3-phosphate dehydrogenase (GAPDH) was used as an endogenous control for IGF-1R expression. The thermocycling conditions were as follows: $95^{\circ} \mathrm{C}$ for $10 \mathrm{~min} ; 40$ cycles at $95^{\circ} \mathrm{C}$ for $15 \mathrm{sec}$ and $60^{\circ} \mathrm{C}$ for $1 \mathrm{~min}$. The primer sequences were: MiR-455, forward 5'-CGAGCTTCCTTCTGCAGGT-3' and reverse 5'-CACCACTGCCATCCCACA-3'; U6, forward 5'-CTCGCT TCGGCAGCACA-3' and reverse: 5'-AACGCTTCACGAATT TGCGT-3'; IGF-1R, forward 5'-TGCGTGAGAGGATTGAGT TTC-3' and reverse 5'-CTTATTGGCGTTGAGGTATGA-3'; and GAPDH, forward 5'-TGCACCACCAACTGCTTAGC-3' and reverse 5'-GGCATGCACTGTGGTCATGAG-3'. miR-455 and IGF-1R mRNA expression levels were quantified by comparing $\mathrm{Cq}$ values (22). Each sample was analyzed in triplicate and repeated at least 3 independent times.

Cell proliferation assay. Cell proliferation was evaluated using Cell Counting kit-8 (CCK-8; Dojindo Molecular Technologies, Inc., Kumamoto, Japan). Cells transfected with miRNA or siRNA were collected, seeded into 96-well plates at a density of 4,000 cells/well, and further incubated for 24, 48, 72 and $96 \mathrm{~h}$, respectively. CCK-8 reagent $(10 \mu \mathrm{l})$ was added into each well, and incubated at $37^{\circ} \mathrm{C}$ for an additional $2 \mathrm{~h}$. Absorbance was measured at a wavelength of $450 \mathrm{~nm}$ using a spectrophotometer.

Transwell cell invasion assay. Transwell chambers with $8 \mu \mathrm{m}$-pore-size filter were used to assess cell invasion ability. The chambers were pre-coated with Matrigel (BD Biosciences, San Jose, CA, USA). Transfected cells were collected and seeded into the upper compartment of the chamber at a density of $1 \times 10^{5}$ cells suspended into $100 \mu \mathrm{l}$ serum free DMEM.

A total of $200 \mu \mathrm{l}$ DMEM containing $20 \%$ FBS was placed in the bottom compartment of the chamber. Following incubation for $24 \mathrm{~h}$, the non-invading cells were removed with cotton swabs. The invading cells were fixed with $100 \%$ methanol, stained with $0.5 \%$ crystal violet, washed with PBS and counted using an inverted light microscope (CKX41; Olympus Corporation, Tokyo, Japan). The assays were performed three independent times.

Target prediction of miRNAs. To predict miRNAs/mRNAs interactions, TargetScan v.6.0 (http://www.targetscan.org/) and microRNA (August 2010 release; www.microrna.org/) were used.

Western blot. Total protein was isolated using radioimmunoprecipitation buffer (Sigma-Aldrich; Merck KGaA, Darmstadt, Germany) supplemented with $0.1 \mathrm{mg} / \mathrm{ml}$ phenylmethylsulfonyl fluoride, $1 \mathrm{mM}$ sodium orthovanadate and $1 \mathrm{mg} / \mathrm{ml}$ aprotinin. Total protein concentration was measured using the bicinchoninic acid protein assay kit (Pierce; Thermo Fisher Scientific, Inc.). Equal amounts of total protein $(30 \mu \mathrm{g})$ were separated in $10 \%$ SDS polyacrylamide gels, transferred to polyvinylidene difluoride membranes (Merck KGaA) and blocked with 5\% milk in TBS containing $0.05 \%$ Tween-20 (TBST) at room temperature for $2 \mathrm{~h}$. Then, the membranes were probed with the following primary antibodies: Mouse anti-human monoclonal IGF-1R (1:1,000 dilution; cat. no. sc-81464; Santa Cruz Biotechnology, Inc., Dallas, TX, USA) and GADPH (1:1,000 dilution; cat. no. sc-51907; Santa Cruz Biotechnology, Inc.), at $4^{\circ} \mathrm{C}$ overnight. Following washing three times with TBST, the membranes were incubated with their respective horseradish peroxidase-conjugated secondary antibody (1:5,000 dilution; 
cat. no. sc-2005; Santa Cruz Biotechnology, Inc.) at room temperature for $2 \mathrm{~h}$. Following three washes in TBST, the bands were visualized with an enhanced chemiluminescence system (GE Healthcare Life Sciences, Chalfont, UK). Band intensities were quantified using the FluorChem imaging system (Alpha Innotec $\mathrm{GmbH}$, Kasendorf, Germany) from at least 3 independent experiments.

Luciferase report assay. The luciferase reporter vectors pGL3-IGF-1R-3'UTR Wt and pGL3-IGF-1R-3'UTR Mut were synthesized by Shanghai GenePharma Co., Ltd. (Shanghai, China).HEK293T cells were transfected with luciferase reporter vector and miR-455 mimics or NC using Lipofectamine 2000. Firefly and Renilla luciferase activities were evaluated $48 \mathrm{~h}$ after transfection using the Dual-Luciferase assay system (Promega Corporation, Madison, WI, USA), and Renilla luciferase activity was normalized to firefly luciferase activity.

Statistical analysis. The results were presented as the mean \pm standard deviation. SPSS 16.0 (SPSS, Inc., Chicago, IL, USA) was used for statistical analysis with two-tailed Student's $t$-test or one-way analysis of variance followed by Student-Newman-Keuls post hoc test. $\mathrm{P}<0.05$ was considered to indicate a statistically significant difference.

\section{Results}

miR-455 is downregulated in melanoma tissues and cell lines. miR-455 expression levels were measured in 22 pair of melanoma tissues and adjacent non-tumor tissues by RT-qPCR. The results revealed that miR-455 was significantly downregulated in melanoma tissues compared with adjacent non-tumor tissues ( $\mathrm{P}<0.05$; Fig. 1A). Subsequently, miR-455 expression was also detected in melanoma cell lines (SKMEL1, A375, HT114, A2058) and human epidermal melanocytes (HEM) using RT-qPCR. The results revealed that miR-455 expression was significantly reduced in all melanoma cell lines compared with HEM $(\mathrm{P}<0.05$; Fig. 1B). The expression levels of miR-455 were lowest in the A375 and HT114 cell lines, therefore A375 and HT114 cell lines were selected for subsequent experiments.

miR-455 inhibits melanoma cell viability and invasion. To assess the functional involvement of miR-455 in melanoma, A375 and HT114 cells were transfected with an miR-455 mimic or NC. RT-qPCR was performed $48 \mathrm{~h}$ following transfection to evaluate the transfection efficiency, and revealed that miR-455 was significantly upregulated in A375 and HT114 cells transfected with miR-455 mimics ( $\mathrm{P}<0.05$; Fig. 2A).

Cell proliferation assays were performed to evaluate the effect of miR-455 on cell growth. As a result of miR- 455 overexpression, cell proliferation in the miR-455 mimic group was significantly decreased in A375 and HT114 cells compared with the $\mathrm{NC}$ groups at 72 and $96 \mathrm{~h}(\mathrm{P}<0.05$; Fig. 2B).

Transwell cell assays were performed to assess the effect of miR-455 on cell invasion. The results demonstrated that miR-455 overexpression significantly inhibited A375 and HT114 cell invasion compared with the NC groups $(\mathrm{P}<0.05$; Fig. $2 \mathrm{C}$ ). These findings suggested that miR-455 may function as a tumor suppressor in melanoma.
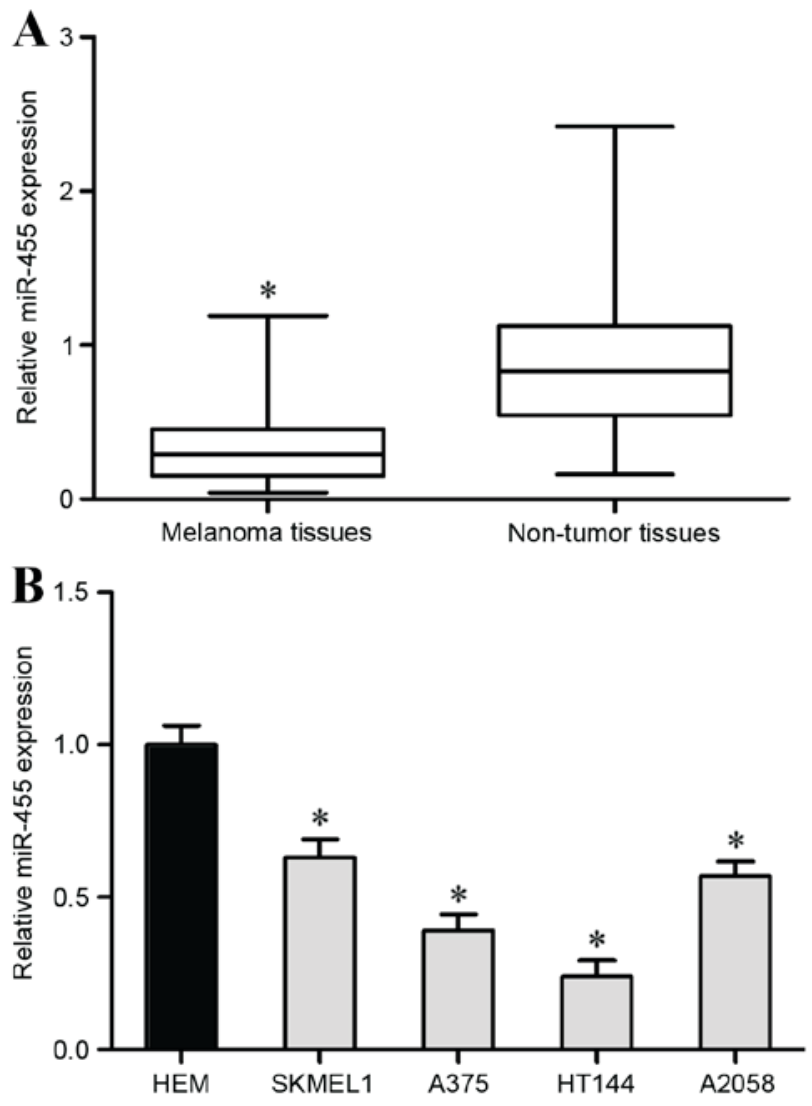

Figure 1. miR-455 is downregulated in melanoma tissues and cell lines (A) Expression levels of miR-455 in melanoma tissues and adjacent non-tumor tissues were measured using reverse transcription-quantitative polymerase chain reaction. (B) The expression of miR-455 in melanoma cell lines (SKMEL1, A375, HT114, A2058) and HEM. "P<0.05 vs. non-tumor tissues or HEM. miR-455, microRNA-455; HEM, human epidermal melanocytes.

$I G F-1 R$ is a direct target of $m i R-455$. To explore the potential target genes of miR-455, TargetScan and microRNA were used. This analysis predicted that IGF-1R was a putative target of miR-455 (Fig. 3A). To identify the regulatory relationship between miR-455 and IGF-1R, a luciferase reporter assay was performed in HEK293T cells. miR-455 overexpression significantly decreased luciferase activity compared with the NC group following transfection with pGL3-IGF-1R-3'UTR Mut but not pGL3-IGF-1R-3'UTR Wt, indicating that miR-455 directly targeted the 3'UTR of IGF-1R (Fig. 3B).

To directly evaluate the effect of miR-455 on IGF-1R expression, western blot and RT-qPCR were performed. The results demonstrated that miR-455 overexpression significantly suppressed IGF-1R expression in A375 and HT114 cells at the mRNA $(\mathrm{P}<0.05$; Fig. $3 \mathrm{C})$ and protein $(\mathrm{P}<0.05$; Fig. 3D) levels. Taken together, these results indicated that IGF-1R was a direct downstream target of miR-455 in melanoma.

This prompted further exploration of whether the suppressive functions of miR-455 in melanoma were induced by IGF-1R. For this purpose, IGF-1R siRNA or control siRNA was transfected into A375 and HT114 cells. Western blotting was performed $72 \mathrm{~h}$ following transfection to assess the transfection efficiency, which revealed that IGF-1R was significantly downregulated in A375 and HT114 cells transfected with IGF-1R siRNA compared with the control siRNA group ( $\mathrm{P}<0.05$; Fig. 3E). Once IGF-1R expression was 

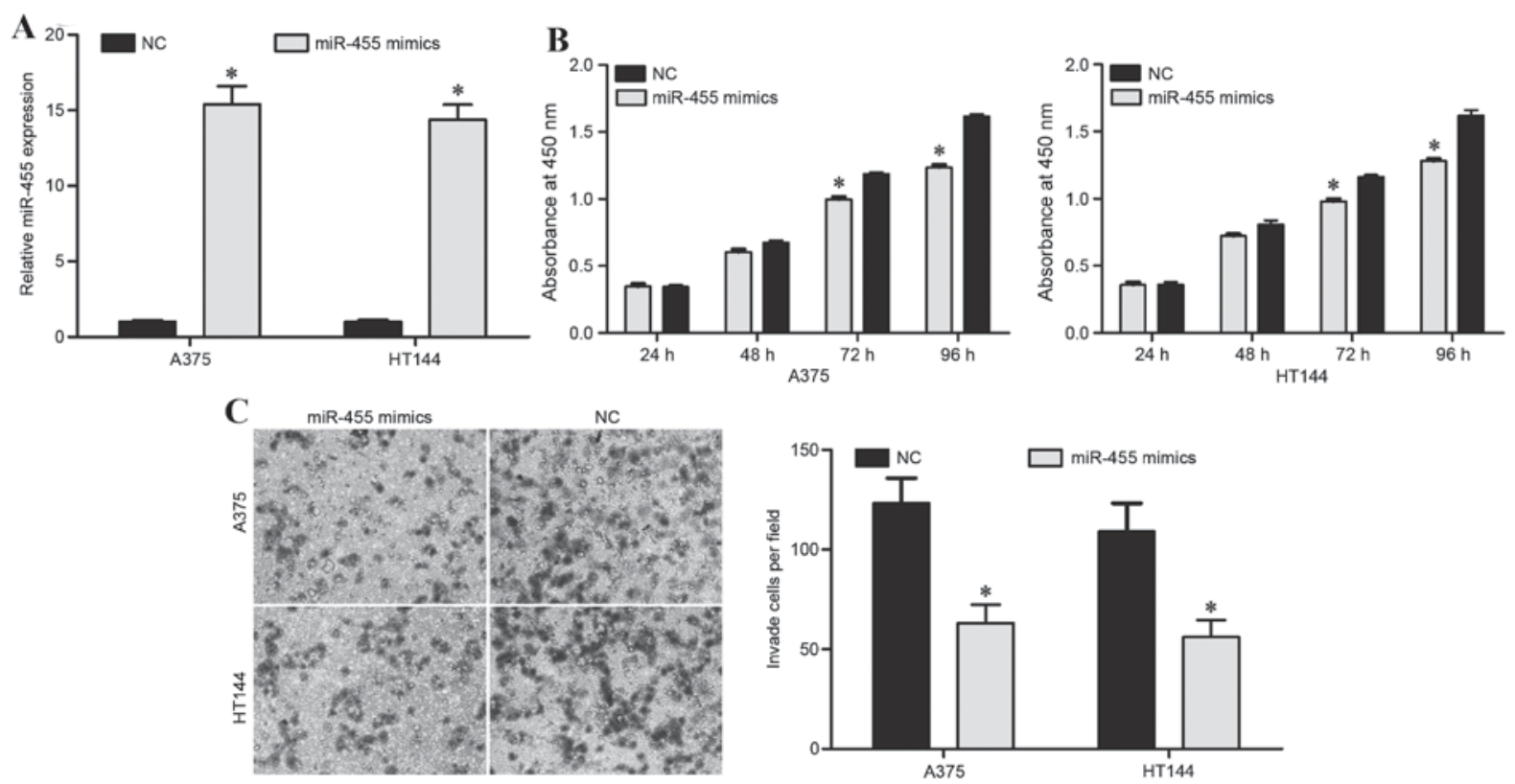

Figure 2. miR-455 inhibits proliferation and invasion of melanoma cells. (A) miR-455 was significantly upregulated in A375 and HT114 cells following transfection with miR-455 mimics, as determined by reverse transcription-quantitative polymerase chain reaction. (B) Effect of miR-455 on proliferation of melanoma cells were evaluated using Cell Counting kit-8. (C) Effects of miR-455 on invasion of melanoma cells were assessed by Transwell invasion assay. "P<0.05 vs. NC. miR-455, microRNA-455; NC, negative control.

effectively depressed from 72 h onwards, A375 and HT114 cells transfected with IGF-1R siRNA exhibited significantly decreased cell proliferation $(\mathrm{P}<0.05$; Fig. $3 \mathrm{~F})$ and invasion $(\mathrm{P}<0.05$; Fig. 3G) compared with the control siRNA group, which was similar with the functions induced by miR-455 overexpression in melanoma cells. Collectively, these findings demonstrated that miR-455 functions as a tumor suppressor in melanoma through directly targeting IGF-1R.

\section{Discussion}

Melanoma has the highest fatality and malignancy of all the skin cancers (23) and the morbidity of melanoma was ranked 5th in males and 7th in females of all malignancies from 1992 to 2010 (24). According to statistical analysis, in $2015 \sim 73,870$ novel melanoma cases and 9,940 deaths due to melanoma occurred in the USA (25). Improvement in the prognosis of patients with melanoma largely depends on increasing the understanding of the molecular mechanisms underlying the carcinogenesis and progression of this malignancy. A number of previous studies have demonstrated that miRNAs function as a novel group of oncogenes and tumor suppressor genes, because their abnormal expression is associated with multiple human cancers, including melanoma, by negatively regulating the expression of cancer-associated genes (26-28). Therefore, miRNAs may be novel targets for therapy in cancers.

In the present study, the expression levels of miR-455 in melanoma tissues and cell lines were investigated. miR-455 was significantly downregulated in melanoma tissues and cell lines compared with adjacent non-tumor tissues and human epidermal melanocytes. This indicated that miR-455 may be involved in melanoma carcinogenesis and progression. Functional studies revealed that ectopic miR-455 expression inhibited the proliferation and invasion of melanoma cells. Furthermore, the present study suggested that miR-455 exerts its tumor suppressive functions by targeting IGF-1R. Taken together, these findings indicated that miR-455 may act as a tumor suppressor in tumorigenesis and development of melanoma through regulation of IGF-1R.

Previous studies have demonstrated that miR-455 is deregulated in multiple human diseases, and contributes to multiple physiological and pathological processes including glioblastoma, steroidogenesis, colorectal cancer, chondrogenesis and osteoarthritis (29-33). Chai et al (33) reported that expression levels of miR-455 were decreased in colorectal tissues, and overexpression of miR-455 inhibited growth and invasion of colorectal cells. Using TargetScan, luciferase report assay, RT-qPCR and western blot, RAF1 was validated as a direct target gene of miR-455 in colorectal cancer (33). These findings suggested that miR-455/RAF1 may represent a new potential therapeutic target for colorectal cancer treatment.

Since the potential molecular mechanism of miR-455 as a tumor suppressor in melanoma was unknown, the present study aimed to identify the mechanism. Identification of target genes of miR-455 is important for elucidation of the functions of miR-455 in carcinogenesis and progression of melanoma, and may provide promising therapeutic targets for patients with melanoma. Initially, the bioinformatic analysis (using TargetScan and microRNA) revealed that IGF-1R may be a potential target for miR-455. Subsequently, this predication was further confirmed by the luciferase report assay. The results demonstrated that miR-455 overexpression decreased luciferase activity in the pGL3-IGF-1R-3'UTR Mut but not the pGL3-IGF-1R-3'UTR Wt, indicating that miR-455 directly targeted the 3'UTR of IGF-1R. Notably, 
A

IGF-1R 3' UTR Wt

hsa-miR-455

$5^{\prime}$...GGCCUCUCCUCUCGUGCACAUAC.

IGF-1R 3' UTR Mut

3' gCuacaucagguUuccGuguau

5 '...GGCCUCUCCUCUCGUCGUGUAC...
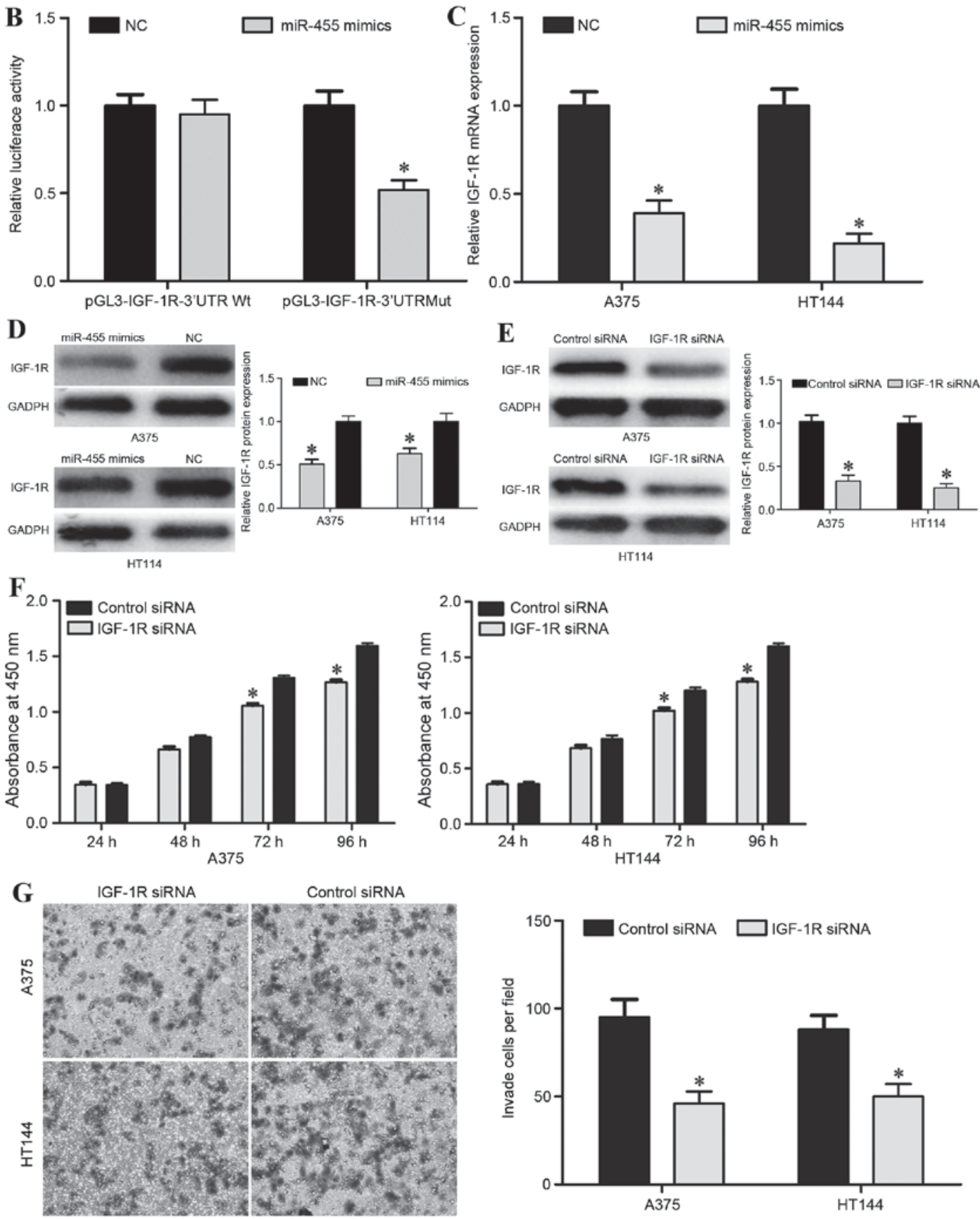

Figure 3. IGF-1R is a direct target gene of miR-455. (A) The 3'UTR of IGF-1R is partially complementary to miR-455. (B) Luciferase reporter assay in HEK293T cells transfected with miR-455 mimics or NC. (C) Reverse transcription-quantitative polymerase chain reaction was performed to measure the IGF-1R mRNA expression levels in A375 and HT114 cells transfected with miR-455 mimics or NC. (D) Western blot analysis of IGF-1R protein expression in A375 and HT114 cells transfected with miR-455 mimics or NC. (E) Western blot analysis of IGF-1R protein expression in A375 and HT114 cells transfected with IGF-1R siRNA or control siRNA. (F) Effect of IGF-1R siRNA on proliferation of melanoma cells was evaluated by Cell Counting kit-8. (G) Effects of IGF-1R siRNA on invasion of melanoma cells were assessed by Transwell invasion assay. ${ }^{*} \mathrm{P}<0.05 \mathrm{vs}$. NC or control siRNA. IGF-1R, insulin-like growth factor 1 receptor; miR-455, microRNA-455; 3'UTR, 3'-untranslated region; NC, negative control; siRNA, small interfering RNA.

the regulatory effect of miR-455 on IGF-1R expression in melanoma cells was measured using RT-qPCR and western blot analysis. The data revealed that miR-455 overexpression dramatically suppressed IGF-1R expression at the mRNA and protein levels in melanoma cells. Finally, IGF-1R knockdown suppressed proliferation and invasion of melanoma cells, which was similar to the effect observed as a result of miR-455 overexpression in melanoma cells. These findings verified that miR-455 targeted IGF-1R to decrease melanoma cell growth and invasion.

IGF-1R, a transmembrane tyrosine kinase receptor of the insulin receptor family, is mainly activated by IGF1 and 
IGF2 in autocrine and paracrine manners (34). It activates multiple downstream signaling cascades, including phosphoinositide 2-kinase/Akt and mitogen activated protein kinase/extracellular signal-related kinase signaling pathways, and is involved in cell proliferation, differentiation, migration, invasion, metastasis and survival (35-38). IGF-1R has been demonstrated to be upregulated in multiple human cancers, including hepatocellular carcinoma, non-small lung cancer, prostate cancer and melanoma (39-42). IGF-1R has been demonstrated to be regulated by microRNAs in cancers, including miR-497 in cervical cancer and pancreatic cancer $(43,44)$, miR-332-5p and miR-181b in glioma $(45,46)$ and miR-133a in hepatocellular carcinoma (47). These studies indicated that miRNAs/IGF-1R based targeted therapy may be a novel treatment for cancer.

In conclusion, the present study confirmed the tumor suppressor function of miR-455 in melanoma, and demonstrated that miR-455 suppressed proliferation and invasion through directly targeting IGF-1R. These findings suggested that the restoration of miR-455 merits investigation as a therapeutic treatment for patients with melanoma.

\section{References}

1. Miller AJ and Mihm MC Jr: Melanoma. N Engl J Med 355 51-65, 2006

2. Terando A, Sabel MS and Sondak VK: Melanoma: Adjuvant therapy and other treatment options. Curr Treat Options Oncol 4: 187-199, 2003.

3. Penna E, Orso F, Cimino D, Vercellino I, Grassi E, Quaglino E, Turco E and Taverna D: MiR-214 coordinates melanoma progression by upregulating ALCAM through TFAP2 and miR-148b downmodulation. Cancer Res 73: 4098-4111, 2013.

4. Baade $\mathrm{P}$ and Coory $\mathrm{M}$ : Trends in melanoma mortality in Australia: 1950-2002 and their implications for melanoma control. Aust N Z J Public Health 29: 383-386, 2005.

5. Coory M, Baade P, Aitken J, Smithers M, McLeod GR and Ring I: Trends for in situ and invasive melanoma in Queensland, Australia, 1982-2002. Cancer Causes Control 17: 21-27, 2006.

6. Jemal A, Siegel R, Ward E, Hao Y, Xu J, Murray T and Thun MJ: Cancer statistics, 2008. CA Cancer J Clin 58: 71-96, 2008.

7. Sosman JA, Kim KB, Schuchter L, Gonzalez R, Pavlick AC, Weber JS, McArthur GA, Hutson TE, Moschos SJ, Flaherty KT, et al: Survival in BRAF V600-mutant advanced melanoma treated with vemurafenib. N Engl J Med 366: 707-714, 2012.

8. Siegel R, DeSantis C, Virgo K, Stein K, Mariotto A, Smith T, Cooper D, Gansler T, Lerro C, Fedewa S, et al: Cancer treatment and survivorship statistics, 2012. CA Cancer J Clin 62: 220-241, 2012.

9. Wagle N, Emery C, Berger MF, Davis MJ, Sawyer A, Pochanard P, Kehoe SM, Johannessen CM, Macconaill LE, Hahn WC, et al: Dissecting therapeutic resistance to RAF inhibition in melanoma by tumor genomic profiling. J Clin Oncol 29: 3085-3096, 2011.

10. He L and Hannon GJ: MicroRNAs: Small RNAs with a big role in gene regulation. Nat Rev Genet 5: 522-531, 2004.

11. Lai EC: Micro RNAs are complementary to 3' UTR sequence motifs that mediate negative post-transcriptional regulation. Nat Genet 30: 363-364, 2002 .

12. Singh TR, Gupta A and Suravajhala P: Challenges in the miRNA research. Int J Bioinform Res Appl 9: 576-583, 2013.

13. Phuah NH and Nagoor NH: Regulation of microRNAs by natural agents: New strategies in cancer therapies. Biomed Res Int 2014: 804510, 2014.

14. Ling H, Fabbri $M$ and Calin GA: MicroRNAs and other non-coding RNAs as targets for anticancer drug development. Nat Rev Drug Discov 12: 847-865, 2013.

15. Ambros V: The functions of animal microRNAs. Nature 431: 350-355, 2004

16. Fabian MR, Sonenberg N and Filipowicz W: Regulation of mRNA translation and stability by microRNAs. Annu Rev Biochem 79: 351-379, 2010.
17. Blower PE, Verducci JS, Lin S, Zhou J, Chung JH, Dai Z, Liu CG, Reinhold W, Lorenzi PL, Kaldjian EP, et al: MicroRNA expression profiles for the NCI-60 cancer cell panel. Mol Cancer Ther 6: 1483-1491, 2007.

18. Sakurai E, Maesawa C, Shibazaki M, Yasuhira S, Oikawa H, Sato M, Tsunoda K, Ishikawa Y, Watanabe A, Takahashi K, et al: Downregulation of microRNA-211 is involved in expression of preferentially expressed antigen of melanoma in melanoma cells. Int J Oncol 39: 665-672, 2011.

19. Medina PP, Nolde M and Slack FJ: OncomiR addiction in an in vivo model of microRNA-21-induced pre-B-cell lymphoma. Nature 467: 86-90, 2010.

20. Obad S, dos Santos CO, Petri A, Heidenblad M, Broom O, Ruse C, Fu C, Lindow M, Stenvang J, Straarup EM, et al: Silencing of microRNA families by seed-targeting tiny LNAs. Nat Genet 43: 371-378, 2011.

21. Saito Y, Liang G, Egger G, Friedman JM, Chuang JC, Coetzee GA and Jones PA: Specific activation of microRNA-127 with downregulation of the proto-oncogene BCL6 by chromatin-modifying drugs in human cancer cells. Cancer Cell 9: 435-443, 2006

22. Livak KJ and Schmittgen TD: Analysis of relative gene expression data using real-time quantitative PCR and the 2(-Delta Delta C(T)) Method. Methods 25: 402-408, 2001.

23. Liu R, Xie H, Luo C, Chen Z, Zhou X, Xia K, Chen X, Zhou M, Cao P, Cao K and Zhou J: Identification of FLOT2 as a novel target for microRNA-34a in melanoma. J Cancer Res Clin Oncol 141: 993-1006, 2015.

24. Siegel R, Ma J, Zou Z and Jemal A: Cancer statistics, 2014. CA Cancer J Clin 64: 9-29, 2014.

25. Siegel RL, Miller KD and Jemal A: Cancer statistics, 2015. CA Cancer J Clin 65: 5-29, 2015.

26. Du B, Wang Z, Zhang X, Feng S, Wang G, He J and Zhang B: MicroRNA-545 suppresses cell proliferation by targeting cyclin D1 and CDK4 in lung cancer cells. PLoS One 9: e88022, 2014.

27. Huang F, Tang J, Zhuang X, Zhuang Y, Cheng W, Chen W, Yao H and Zhang S: MiR-196a promotes pancreatic cancer progression by targeting nuclear factor kappa-B-inhibitor alpha. PLoS One 9: e87897, 2014

28. Tao J, Wu D, Xu B, Qian W, Li P, Lu Q, Yin C and Zhang W: MicroRNA-133 inhibits cell proliferation, migration and invasion in prostate cancer cells by targeting the epidermal growth factor receptor. Oncol Rep 27: 1967-1975, 2012.

29. Ujifuku K, Mitsutake N, Takakura S, Matsuse M, Saenko V, Suzuki K, Hayashi K, Matsuo T, Kamada K, Nagata I and Yamashita S: MiR-195, miR-455-3p and miR-10a (") are implicated in acquired temozolomide resistance in glioblastoma multiforme cells. Cancer Lett 296: 241-248, 2010.

30. Hu Z, Shen WJ, Kraemer FB and Azhar S: MicroRNAs 125a and 455 repress lipoprotein-supported steroidogenesis by targeting scavenger receptor class B type I in steroidogenic cells. Mol Cell Biol 32: 5035-5045, 2012.

31. Li X, Zhang G, Luo F, Ruan J, Huang D, Feng D, Xiao D, Zeng $\mathrm{Z}, \mathrm{Chen} \mathrm{X}$ and $\mathrm{Wu} \mathrm{W}$ : Identification of aberrantly expressed miRNAs in rectal cancer. Oncol Rep 28: 77-84, 2012.

32. Swingler TE, Wheeler G, Carmont V, Elliott HR, Barter MJ, Abu-Elmagd M, Donell ST, Boot-Handford RP, Hajihosseini MK, Münsterberg A, et al: The expression and function of microRNAs in chondrogenesis and osteoarthritis. Arthritis Rheum 64: 1909-1919, 2012.

33. Chai J, Wang S, Han D, Dong W, Xie C and Guo H: MicroRNA-455 inhibits proliferation and invasion of colorectal cancer by targeting RAF proto-oncogene serine/threonine-protein kinase. Tumour Biol 36: 1313-1321, 2015.

34. Zhao X, Dou W, He L, Liang S, Tie J, Liu C, Li T, Lu Y, Mo P, Shi Y, et al: MicroRNA-7 functions as an anti-metastatic microRNA in gastric cancer by targeting insulin-like growth factor-1 receptor. Oncogene 32: 1363-1372, 2013.

35. Baserga R, Peruzzi F and Reiss K: The IGF-1 receptor in cancer biology. Int J Cancer 107: 873-877, 2003.

36. Cao Z, Liu LZ, Dixon DA, Zheng JZ, Chandran B and Jiang BH: Insulin-like growth factor-I induces cyclooxygenase-2 expression via PI3K, MAPK and PKC signaling pathways in human ovarian cancer cells. Cell Signal 19: 1542-1553, 2007.

37. Christopoulos PF, Msaouel P and Koutsilieris M: The role of the insulin-like growth factor-1 system in breast cancer. Mol Cancer 14: 43, 2015. 
38. Gryko M, Kiśluk J, Cepowicz D, Zińczuk J, Kamocki Z, Guzińska-Ustymowicz K, Pryczynicz A, Czyżewska J, Kemona A and Kędra B: Expression of insulin-like growth factor receptor type 1 correlate with lymphatic metastases in human gastric cancer. Pol J Pathol 65: 135-140, 2014.

39. Wang YH, Wang ZX, Qiu Y, Xiong J, Chen YX, Miao DS and De W: Lentivirus-mediated RNAi knockdown of insulin-like growth factor-1 receptor inhibits growth, reduces invasion and enhances radiosensitivity in human osteosarcoma cells. Mol Cell Biochem 327: 257-266, 2009.

40. Wang YH, Han XD, Qiu Y, Xiong J, Yu Y, Wang B, Zhu ZZ, Qian BP, Chen YX, Wang SF, et al: Increased expression of insulin-like growth factor-1 receptor is correlated with tumor metastasis and prognosis in patients with osteosarcoma. J Surg Oncol 105: 235-243, 2012.

41. Scharf JG and Braulke T: The role of the IGF axis in hepatocarcinogenesis. Horm Metab Res 35: 685-693, 2003.

42. Kanter-Lewensohn L, Dricu A, Wang M, Wejde J, Kiessling R and Larsson O: Expression of the insulin-like growth factor-1 receptor and its anti-apoptotic effect in malignant melanoma: A potential therapeutic target. Melanoma Res 8: 389-397, 1998.
43. Luo M, Shen D, Zhou X, Chen X and Wang W: MicroRNA-497 is a potential prognostic marker in human cervical cancer and functions as a tumor suppressor by targeting the insulin-like growth factor 1 receptor. Surgery 153: 836-847, 2013.

44. Xu JW, Wang TX, You L, Zheng LF, Shu H, Zhang TP and Zhao YP: Insulin-like growth factor 1 receptor (IGF-1R) as a target of MiR-497 and plasma IGF-1R levels associated with TNM stage of pancreatic cancer. PLoS One 9: e92847, 2014.

45. Lian HW, Zhou Y, Jian ZH and Liu RZ: MiR-323-5p acts as a tumor suppressor by targeting the insulin-like growth factor 1 receptor in human glioma cells. Asian Pac J Cancer Prev 15: 10181-10185, 2014

46. Shi ZM, Wang XF, Qian X, Tao T, Wang L, Chen QD, Wang XR, Cao L, Wang YY, Zhang JX, et al: MiRNA-181b suppresses IGF-1R and functions as a tumor suppressor gene in gliomas. RNA 19: 552-560, 2013

47. Zhang W, Liu K, Liu S, Ji B, Wang Y and Liu Y: MicroRNA-133a functions as a tumor suppressor by targeting IGF-1R in hepatocellular carcinoma. Tumour Biol 36: 9779-9788, 2015. 